\title{
Overall Thinking of China's Eighth Institutional Reform under the Perspective of System Theory
}

\author{
Ziyun Yang \\ School of Public Administration and Emergency Management, Jinan University, Guangzhou, China \\ Email: 503804668@qq.com
}

How to cite this paper: Yang, Z.Y. (2019) Overall Thinking of China's Eighth Institutional Reform under the Perspective of System Theory. Open Journal of Social Sciences, 7, 246-258.

https://doi.org/10.4236/jss.2019.75022

Received: May 7, 2019

Accepted: May 26, 2019

Published: May 29, 2019

Copyright $\odot 2019$ by author(s) and Scientific Research Publishing Inc. This work is licensed under the Creative Commons Attribution International License (CC BY 4.0).

http://creativecommons.org/licenses/by/4.0/

\section{(c) (i) Open Access}

\begin{abstract}
The reform of Chinese government institutions is a comprehensive system reform. System theory provides a theoretical perspective for the overall reform of the system engineering of Chinese government institutional reform, and provides an analytical framework for scientific understanding of the new era of socialism reform. In 2018, compared with the first seven institutional reforms, the reform of Chinese government institutions has shifted from unilateral one-way reform to comprehensive and systematic reform. The systematic nature of the eighth institutional reform is embodied in the purpose of institutional reform, the integrity of the reform of the party and government, the hierarchical nature of the main body and functions, and the environmental adaptability of emergency management and normal management. On this basis, System Theory provides ideas for thinking about how to continue to promote the future of institutional reform in China, namely, the direction of differential synergy, overall optimization, and self-organization. Therefore, the use of system theory to promote and analyze the reform of Chinese government institutions not only helps to understand the scientific nature of the new round of institutional reforms in 2018, but also helps to understand the development of government reforms in the future.
\end{abstract}

\section{Keywords}

System Theory, Institutional Reform, Overall Reform

\section{Introduction}

China's social development has entered a new era, and a new round of institutional reforms needs to respond to the demands of the new era. Under the background of the new era, the overall layout of the "five in one" and the coordinated 
development of the "four comprehensive" strategic layout are inseparable from the promotion of the unified reform by Chinese government agencies. This requires the reform of Chinese institutions in the new era to be incorporated into political, administrative, economic and social aspects. The arrival of a new era means not only a change in the background of China's institutional reforms, but also a new change in all the problems and challenges of institutional reform. The reform of the administrative system, especially the institutional reform, as an important part of China's national governance system and the modernization of governance capabilities, faces the challenges of the new tasks brought about by the new era. China is in a period of advanced reform of the state governance system. The requirement to continuously improve modern governance capabilities is rooted in a new round of institutional reforms.

With the advancement of seven institutional reforms, the reform of the Chinese state's institutions has entered a period of tackling difficulties. Comprehensive and integrated reform has become a breakthrough in the bottleneck of reform. From the Third Plenary Session of the 18th CPC Central Committee emphasizes "more emphasis on the systemic, holistic, and synergistic nature of reform" to the party's 19th National Congress stresses that "deepening party and state reform is a systematic project", government reform ideas and top-level design both reflect the systemic requirements. General Secretary Xi Jinping pointed out that "there is no need to seek a whole world". Many scholars have analyzed the new round of institutions from a holistic perspective. Unlike many previous studies, the systemic perspective also explores and emphasizes holism, but does not examine the integrity of the system in isolation, but examines its overall relationship with parts, levels, structures, functions, and environments. Sexuality provides an analytical framework for studying the reform of Chinese government institutions. From the perspective of system theory, it analyzes the overall reform of the eighth institution of China, and explores the logic of the reform of the government and the government in the system and the development direction of the government.

\section{System Theory and Its Analysis Framework}

System theory is the study of the general model, structure and law of the system. It studies the common characteristics of various systems, quantitatively describes its functions by mathematical methods, and seeks and establishes the principles and mathematical models applicable to all systems. In the 1940s, the Austrian biologist Bertalanffy published an article on "General System Theory", marking the birth of system theory. Bertalanffy uses biological objects as a system to explore the general principles that apply to systems. He believes that the system has basic attributes such as integrity, hierarchical order, and graduality. System theory is initially applied to research in the biological field. With the advancement of time, the scope of application of system theory has gradually broadened and is continuously being used in many fields. Modern systems theory believes 
that systems are ubiquitous and systematic thinking is also universally usable. System theory has also been applied in the field of social science to analyze the development laws and changing laws of various social systems. Some modern systemic scholars generalize the rules of the system development and change, and summarize the basic laws of self-organized (woven) emergent law, differential synergy law, structural function law, and overall optimization law [1]. From the perspective of system theory, the government itself is an open system, a self-organization. The reform of government institutions is also a systematic project. The institutional reform of the government has the characteristics of abrupt changes in system theory. The mutation here does not mean a fierce mutation in the reform process, but rather that the government system moves from one state to another through stable reform. Institutional reforms have made the development and evolution of our government system more likely and sustainable.

The reform of government institutions under the perspective of research systems theory requires an analytical framework. Since the 20th century, the object of scientific research has become more complex, the number of constituent elements in the system has increased dramatically, and the level and structure have become more complicated. System theory provides a good perspective to study complex and large systems. We regard the institution as a system, draw on the theory of system theory and its synergy theory, and construct a government reform analysis framework based on the four basic characteristics of the system. The systemic perspective also examines the purpose of the system. Purposefulness is a good response to the direction of system changes. Taking the purpose of the system as the starting point, we can analyze the general trend of institutional reform. Integrity is also an important feature of the system. The analysis of the system is inseparable from the analysis of its integrity. Under the system theory, the government agency is a complete system composed of many departments. At the same time, the government can be seen as an important subsystem in the entire social system. Due to the dual nature of the government, the analysis of government institutional reform must proceed from the coordination of various elements within the government system, and from the connection between the government and the social system in which it is located. The third dimension examines how the reform of the institutional organization advances the hierarchy of the system. The tomosynthesis of the system can be divided into structural levels and levels in functions. The "have a number of times" mentioned in this institutional reform is more reflective of the hierarchy of reforms that focus on the system. Finally, the system is an open system. The government also has an open character. This means that there is a mutual exchange between the government and the environment, and the analysis system needs to explore the relationship between the government and the environment. Environmental adaptability in system theory can well reflect the connection between the system and the external environment. This reform of government institutions has em- 
bodied systemicity through overall planning, and further promoted the purpose, integrity, hierarchy and environmental adaptability of the government system. The introduction of the analysis of these four basic characteristics from the perspective of system theory can better grasp the new round of comprehensive system planning of government agencies. System theory can well describe the role of elements, levels, structures, functions, and environmental factors of institutional reform in the overall development of the system and their relationship with each other. Our government institutions are in the ascendant stage of system development. Through institutional reforms, the quality of the constituent elements of our party and government has been continuously improved, the structure has become increasingly stable and optimized, functions have been integrated and strengthened, and the relationship with the environment has become increasingly close [2]. The overall thinking of government institutional reform under the system theory is not a simple arithmetic addition of the nature and function of each element, but an organic combination.

\section{The Unilateral One-Way and Fragmentation Characteristics of the First Seven Government Institutional Reforms}

Starting from the reform and opening up in 1978, China has undergone several institutional reforms. Although institutional reform is considered to be the government's own revolution, the driving force for government institutional reform often comes from outside. Reform and opening up is such an opportunity. The economic system reform has put forward new requirements for government agencies, driving the reform of the administrative system in parallel with the reform of the economic system. Looking back at the 40 years of government institutional reform, China's institutional reforms mainly focus on the streamlining of institutions and personnel, the transformation of government functions, the management system and institutional reform, and the restructuring of power structure. The level of reform has changed from shallow to deep, and the resistance to reform has been increasing.

\subsection{Institutional Reforms from 1976 to 2003}

Institutional reforms carried out between 1978 and 1998 focused on institutional and staff streamlining and the transformation of government functions. In order to eliminate the bloated government agencies and government personnel, the Chinese government has carried out several rounds of government agencies and functional reforms. Institutional reform is to change the economic management function as the main line, and adjust the institutional personnel to meet the needs of the market economic system. The reform mainly adopted measures of "merging departments and streamlining personnel" and adjusting government institutions to adapt to the market economic system. However, as the country's overall management system has not undergone major changes, there has been 
no major change in government functions. Therefore, after several reforms, government agencies and personnel have experienced rebound and resurgence to varying degrees [3]. Institutional reforms have instead plunged into a cycle of cycles that have been streamlined and re-expanded. Along with the deepening of institutional reforms, the resistance to institutional reforms has gradually increased, and the difficulty has become greater and greater, and the problems faced have become more profound and complex. The institutional reforms after 2003 focused on the government's social management and public service functions, strengthening and improving macroeconomic regulation and control [4]. After institutional reform, the transformation of government functions has shifted from focusing on economic development to public services. Its symbol is the service-oriented government construction proposed after the fifth institutional reform [5]. The reform of the government's institutions focused on solving "internal operational problems", deepening the reform of the state-owned assets management system, improving the macro-control system, improving the financial supervision system, and continuing to promote the reform of the circulation management system.

\subsection{Institutional Reforms from 2003 to 2013}

In 2008, institutional reform began to explore the large-scale system of organically unified functions, and rationalized departmental responsibilities by integrating and integrating some departments with similar functions. The strengthening and integration of social management and public service departments in this institutional reform reflects the reform ideas that focus on people's livelihood. In 2013, the institutional reform focused on transforming functions and rationalizing the relationship of duties, and steadily pushed forward the reform of the large-scale system. The reform of government institutions has also begun to move from the original simple institutional adjustment to the construction of the mechanism. The three plenary sessions of the 18th session emphasized that "it is necessary to pay attention to the systemic, holistic and synergistic nature of reform", establish a comprehensive and deepening reform leading group, and be responsible for reforming the overall design, overall coordination, overall promotion, and supervision. The seventh reform, the establishment and improvement of the administrative operation mechanism has become the focus and focus of reform. The basic administrative operation mechanisms, such as the democratic decision-making system, the government affairs open system, the government procurement system, the administrative accountability system, the government performance management system, the citizen participation system, and the expert consultation system, are gradually being established and improved. However, the reform of the administrative operation mechanism has been subjected to great reforms, and most of them are in the stage of piloting. The adjustment of the organization and the establishment of the operational mechanism require systematic coordination. 
All in all, the seven institutional reforms since the reform and opening up have been characterized by fragmentation and lack of systemicity. Institutional reform is a systematic project. The previous seven reforms were periodic adjustment reforms of quantitative thinking characterized by "fine soldiers and simple administration" [6]. The reforms are all unilateral government institutional reforms, shackled in the administrative field and economic management departments, and less involved in political and legal departments and party organizations. Although the seventh institutional reform began to focus on systemic, holistic and synergistic, the systemic nature of reform is a low-level, low-level systemic. Individual reforms and unilateral reforms remain the main elements of the first seven institutional reforms. Although it can produce results in a short period of time, the unilateral single reform is only a relief of social symptoms, and does not fundamentally solve the problem. Reform requires a systemic perspective to provide a sustainable path to reform [7].

\section{Overall Thinking: The Specific Embodiment of the Top-Level Design System Vision}

The new round of institutional reforms carried out by China in 2018 is a reform that has taken turns. Institutional reform in 2018 is a continuation and advancement of the seventh institutional reform, but it is different from the previous institutional integration. In 2018, the institutional reform was transformed from the original simple streamlined reform thinking to a systematic thinking integration organization organization department, rationalizing departmental relations, and promoting the modernization of the national governance system and governance capacity. Overall planning reforms to strengthen systemicity to break down the fragmentation of previous reforms will touch more interest groups and cover a wider range. Therefore, the new round of institutional reform is a systematic reform with a focus on restructuring, reflecting the characteristics of promoting the structural optimization of government agencies.

\subsection{Overall Reform Focus on Systemic Purpose}

The institutional reform since the reform and opening up has been based on the fact that the original administrative agencies and administrative systems have been unable to adapt to the socialist market economy. Adapting to economic system reform has become the core purpose of institutional reform initiatives. Internally, institutional reform is largely aimed at improving efficiency, reducing the cost and pressure of social management, and improving the quality of bureaucratic teams. The purpose of institutional reform is multiple and complex, and it is also advancing with the times. Along with the continuous advancement of state institutional reforms, the institutional function system has completed a major shift to the institutional function system under the conditions of a socialist market economy. In the new stage, the purpose of the eighth institutional reform is not simply to adapt to "adaptation", but to achieve high-quality devel- 
opment of the socialist market economy and modernization of the national governance system and governance capacity. Institutional reform has gradually changed from extensional reform to intrinsic development. In the huge institutional reform system project, this reform reflects the reform ideas of promoting overall efficiency and high quality development. Deepening the reform of the party and state institutions must focus on optimizing synergy and efficiency. This is a systematic requirement for institutional reform. The overall thinking of government institutional reform reflects the upgrading of reform ideas and the evolution towards a systematic approach.

\subsection{Overall Reform Focus on System Integrity}

The reform of the party, government, and military organizations has also reflected the integrity of this institutional reform. China is in the critical area of reform, and the overall reform of the party, government and military groups from a systematic point of view has become a breakthrough point in this period. "We must coordinate the establishment of relevant institutions and the configuration of similar functions, rationalize and optimize the responsibilities of the party departments, state organs, group organizations, and institutions, promote cross-military reforms, enhance party leadership, improve government execution, and stimulate groups. The vitality of the group organization and social organization will enhance the combat effectiveness of the people's army and enable all kinds of institutions to be organically connected and coordinated". The reform of the party and government forces also means that the reform covers economic, political and social system reforms, and the reforms enable the three to interact with each other, coordination and harmonious operation. The system-integrated reform focused on the integrity of the system and responded to the problem of institutional fragmentation and reform fragmentation. "For the first time, the functional systems of the party and state institutions are clearly divided into important components such as the party's leadership system, government governance system, armed force system and group work system". The functional system of the party and state institutions is a socialist system with Chinese characteristics, an important sub-element. The core focus of coordinating the reform of various institutions is the institutional reform of the party. Under the Chinese system, it is not realistic to consider only the reform of government institutions and the institutional reforms that do not involve the party. The Communist Party of China is the ruling party in a leading position. Coordinating the reform of various institutions is a part of the party's overall strategic deployment and the top-level design of the organization. In terms of scope, the reform of the party and government and the reform of government institutions is an all-round holistic reform. It is difficult to implement system reforms only by relying on sub-elements within the system. Reforms in any one area are affected by reforms in other areas and will involve reforms in other areas. The reforms in the field are interrelated and mutually influential. The party's leader- 
ship mechanism at the level of governance of the country can play an overall coordinated role in deepening the reform of the group. The overall reform of the party, government and military groups reflects the integrity and breaks through the reform logic of the past unilateral government institutional reform. The systematization and integrity of the reform created conditions for the deepening of this institutional reform.

\subsection{Overall Reform Focus on System Level}

In the first seven reforms, the characteristics of the different levels of government agencies in China showed the characteristics of "upper and lower general". The responsibilities of the same structure can easily lead to the problem of "segmentation of the government" and hinder the improvement of government efficiency. In the institutional adjustment of the State Council, local governments lack the autonomy of institutional reform. Institutional reform in 2018 mentioned "to optimize the local institutional setup and functional allocation, and to build a work system that runs smoothly from the central to the local, is full of vitality, and prohibits the work". Coordinating the establishment of central and local institutions and functions, we must proceed from rationalizing the relationship between the central and local governments. The key entry point is the setting of "rights of affairs". In this reform of government institutions, the party and the state have made major adjustments in the "rights of affairs". Through the division of the three types of "rights of affairs", the central authority is responsible for the central authority's power and responsibility relationship and the power management system. In the division of the power of affairs, the financial power is also a core part. The reform promoted the adjustment of administrative power based on financial affairs. The locality has been given greater autonomy in reform and has the "right to power" to set up and configure the hierarchy and its functions. The central authorities decentralized the right to administrative reform, allowing local institutions to set up according to the economic and social characteristics of the region, which is conducive to fully stimulating local enthusiasm, highlighting the vitality of local reform, and improving the operational efficiency of local governments. The "Decision" in "giving more autonomy to provincial and below institutions" is an important breakthrough in systematically promoting the optimization of the government's responsibility system [8]. The division of functions between the central and central regions emphasizes that the central government concentrates on grasping major events and seeking overall, we must fully mobilize local enthusiasm and do a good job according to local conditions.

\subsection{Overall Reform Focus on the Environmental Adaptability of the System}

The system is an open system with a certain connection to the environment. Changes in the environment can lead to changes in system characteristics and 
internal structure. The change and development of government management depends not only on the interconnection and interaction between its internal components, but also on its interaction and interaction with the administrative environment [9]. Therefore, government machines also need to improve environmental adaptability. Emergency management and normal management are two important aspects of government management and are highly connected. The administrative environment is used as the boundary between emergency management and normal management. Normal management applies to the normal administrative environment. Once a sudden incident breaks out, normal social order is broken. Simple normal management cannot meet the requirements of abnormal administrative management. Emergency management and normal management are connected and complementary. Coordinate emergency management and normal management to ensure the healthy operation and coordinated development of society. The establishment of the emergency management department in this institutional reform reflects the environmental adaptability of system reform. Uncertainty, destructiveness and proliferation of emergencies require that government emergency management must be fast, coordinated and efficient. Previously, the responsibility for emergency management of various types of disasters in China was dispersed among different government departments. The diversification of duties and the multi-head management coordination caused by departmental boundaries are difficult and inefficient, and also cause a lot of duplication of construction and waste. The new round of institutional reform integrates the emergency management responsibilities of various departments, including the duties of the State Administration of Work Safety, the fire management responsibilities of the Ministry of Public Security, the disaster relief duties of the Ministry of Civil Affairs, the prevention of geological disasters by the Ministry of Land and Resources, and the Ministry of Water Resources. Flood and drought disaster prevention, grassland fire prevention of the Ministry of Agriculture, forest fire prevention related duties of the State Forestry Administration, etc. The newly formed emergency management department not only merged the disaster relief and disaster prevention responsibilities scattered in various departments, but also integrated the emergency management responsibilities of the General Office of the State Council. The establishment of the emergency management department of the institutional reform supplemented the vacancy of the country's normal management and realized the combination of emergency management and normal management.

\section{The Future Issues of Government Institutional Overall Reform}

Institutional reforms use a unified thinking system to systematically promote the all-round optimization of government agencies to achieve harmony, organic and synergy between system elements. With the gradual deepening of institutional reforms, the overall thinking needs to be gradually advanced. At present, the 
coordination of government agencies is at a relatively shallow stage of coordination of departmental relations. System theory provides direction for the future issues of government agencies from three levels, namely, differential synergy, overall optimization, and self-organization.

\subsection{Coordinating Different Agencies to Differentiate Synergies}

Differences exist in all systems and exist in the overall elements, levels, and functions within the system. The government system is a complex giant system. The elements of the government system, that is, the collaborative relationship between departments, the interconnection governance between institutions is linked to the effects of institutional reform. Coordinating reforms between different sectors and agencies is not about eliminating borders. Under Weber's bureaucracy, the specialization of government functions will inevitably lead to the differentiation of government institutions. Even through systematic institutional reforms, the boundaries and differences between institutions cannot be eliminated. Institutional co-ordination must recognize the differences between government agencies, and differences need to be coordinated as a path of advancement. For modern governments, cross-sector collaboration between different agencies is a challenge. Coordinating the reform of different institutions focuses on synergy and integration. Through the review and analysis of the eight government institutional reforms, it is not difficult to find that China's administrative reforms are to integrate departments in the form of "demolition and cooperation", to construct the framework of government organizations, and the functional relations before the theoretical departments. Simple and repetitive "demolition" is a state in which there is no way to achieve the ideal inter-departmental differences but synergy. In order to realize the organic integration and organic synergy of the government, the reform of government institutions needs to break out of the traditional bureaucratic arrangement of departmental constraints. Under the premise of recognizing the differences between the departments, the traditional departmental mutual regulation has been transformed into a public goal and an integrated central institution has been established. Integrated central institutions play a central role in the entire government system [10]. The government has a large internal system with many sub-groups. The integrated hub plays a role in communicating and communicating information among departments, and can form and lead various types of integration teams to maximize the synergy between government resources and government departments.

\subsection{Overall Measures to Optimize Overall}

Overall optimization is the trend and direction of government agency development. The development direction of overall optimization refuses to look at the reform of government institutions with that kind of absolute decomposition and analytical thinking. Systematic theory can provide a holistic image of a system 
that is organically linked to features. The reform of government institutions is a systematic project, and reforms are inseparable from supporting policies and feasible measures. The reform of policies and measures is a driving force for the reform of government institutions in China, ensuring that reforms are feasible and smooth. Reform requires systematic breakthroughs, scientific design systems, and reform programs covering multiple fields. Reforms in various fields must be coordinated and connected to each other. Coordination in the context of the system is not just about integrity. The reform of government institutions should promote some key reforms and key reforms with a systematic and holistic concept.

At the same time, it is equally necessary to co-ordinate existing and past measures. Government institutional reform is not a one-step process, often characterized by gradual nature, influenced by the degree of development of the market and civil society. From the "crossing the river by feeling the stones" to the gradual advancement of the reform of the large-scale system, its successful realization reflects the characteristics of the layer-by-layer advancement of China's institutional reform and the gradual reform. Coordination requires the convergence of existing and past measures, and the requirements for stability and continuity of measures.

\subsection{Coordinating Reforms and Goals with Government Self-Organization}

The institutional reform of the government is actually the process of self-organization of government agencies. The degree of self-organization of the system is related to the system's own development capabilities. The higher the degree of self-organization of a system, the more advanced and sustainable it is. The status quo of government agencies in China is characterized by low self-organization and the characteristics of "segmentation" and "fragmentation". The low degree of self-organization may lead to the fact that our government agencies are excellent in the top-level design, but they work together to rub each other. Promote the rational operation of government agencies, and the rational docking between institutions needs to continuously improve the degree of self-organization of the Chinese government. Self-organization is the process of the synergy of the self-organization of the universe system, and the orderly evolution of the system structure and function in space and time. The institutional reform and the modernization of governance capacity are two levels of self-organization of the Chinese government. Self-organization is the process of the synergy of the self-organization of the universe system, and the orderly evolution of system structure and function in space and time [1]. Institutional reforms must continue to coordinate the internal structure of government institutions and external governance capabilities. In the new round of reforms, China has adopted institutional reforms to achieve the goal of improving the modernization level of governance capabilities. Taking the modernization of governance capacity as the goal of reform, and pushing down institutional reforms, it reflects 
the changes in external functions that require new changes in the internal structure. Coordinating reforms and goals, that is, the reform of institutional reforms and the modernization of governance capabilities are directly related to the degree of self-organization of government agencies and the degree of self-construction. Constantly adjust the degree of fit between reforms and goals, so that the degree of self-organization of government agencies will continue to improve, and they will have the ability to sustain development. At the same time, whether it is to promote modernization through institutional reform, or to modernize the governance capacity, both paths need to promote the achievements of further strengthening the administrative system reform in China, thus improving the self-organization of the government system.

\section{Conclusions}

In short, the perspective of system theory provides a different perspective for understanding and grasping the overall thinking in government institutional reform from a macro perspective. It requires system theory as the basis to understand the overall thinking in the reform of government institutions, and provides ideas for promoting the overall process of institutional reform. In the departmental reforms, departmental differences can be promoted through the establishment of an integrated systemic central organization. The reform of the overall organization should promote the top-level design of science with the overall thinking of system theory, and promote the key reforms and key reforms with the partial breakthrough thinking in the system, and at the same time put forward the requirements for the continuity of reform measures. Institutional reforms continue to improve the degree of self-organization of the government through overall measures and objectives, and improve its ability to sustain development.

At the same time, the reform of government institutions is an important proposition for the development of the Chinese government. This study uses system theory as an entry point to study the eighth Chinese government institutional reform, and proposes the future direction of government institutional reform under the systemic perspective. At present, this study has broadened the application of system theory in public management research and enriched the related research of system theory. However, this study only discusses the systemic problems of government institutional reform at the central government level. Observing the top-level design of government institutional reform from a relatively macro perspective does not involve how to implement the practice of institutional reform. In the previous seven institutional reforms, local governments have experienced varying degrees of invalidity in implementing institutional reforms. At the local government level, is the effect of the system reform of the new round of institutional reforms weakened as before? If the systemic integrated planning reform goes down to the grassroots civil servants, does it still have the characteristics of system coordination? This is the direction we need to seriously think about and explore in the future. 


\section{Conflicts of Interest}

The author declares no conflicts of interest regarding the publication of this paper.

\section{References}

[1] Wu, J. (2008) System philosophy. People’s Publishing House, Beijing.

[2] Chang, S. (2011) From Classical System in the Case of Modern System Theory. Chinese Journal of Systems Science, 19, 1-4.

[3] Pan, X. and Lv, F. (2011) Research on the Development Trend of China's Administrative System Reform since Reform and Opening. Journal of Chinese Academy of Governance, 5, 17-21.

[4] Zhou, Z., Xu, Y. and Chen, Y. (2016) A Review of Institutional Reform over the Past 30 Years from the Perspective of Change Management. Social Sciences in China, 37, 57-74. https://doi.org/10.1080/02529203.2015.1088623

[5] Zhu, Q. (2017) Three Transformations of Government Functions: The Return of Power-Centered Reform. The Journal of Jiangsu Administration Institute, 6, 91-98.

[6] Zhu, G., Ding, Y., Wang, T. and Zhang, Y. (2018) Profound Changes in the Integrity of the Party and State Institutions.

http://news.nankai.edu.cn/mtnk/system/2018/04/19/000377698.shtml

[7] Xu, K. (2014) On the Systematic Planning and Breakthrough of Reform. Jiangsu Social Sciences, 1, 6-10.

[8] Decision of the Central Committee of the Communist Party of China on Deepening the Reform of the Party and State Organizations.

http://www.xinhuanet.com//politics/2018-03/04/c_1122485476.htm

[9] Wang, S. and Li, R. (2013) Comparative Analysis of Government Normal Management and Emergency Management. Journal of the Party School of Tianjin Committee of the CPC, 15, 46-50.

[10] Huang, X. (2018) History of Institutional Reform and Its Inner Logic. Administration Reform, 5, 18-23. 